\title{
A global monthly climatology of oceanic total dissolved inorganic carbon: a neural network approach
}

Daniel Broullón et al.

Correspondence to: Daniel Broullón (dbroullon@iim.csic.es)

The copyright of individual parts of the supplement might differ from the CC BY 4.0 License. 
Table S1. RMSE (bias) between measured and computed $\mathrm{TCO}_{2}$ concentrations in several time series. Units are micromole per kilogram $\left(\mu \mathrm{mol} \mathrm{kg}{ }^{-1}\right)$. *There is only one sample below $500 \mathrm{~m}$.

\begin{tabular}{lccccccccc}
\hline Depth range & \multirow{2}{*}{ BATS } & HOT & ELOHA & ICELAND & IRMINGER & \multirow{2}{*}{ K2 } & KNOT & OWS & KERFIX \\
\hline $0-50 \mathrm{~m}$ & $8.7(2.7)$ & $5.8(-2.6)$ & $4.4(-0.2)$ & $7.8(7.1)$ & $5.3(-0.1)$ & $5.3(0.3)$ & $8.5(-1.3)$ & $10.1(-5.3)$ & $10(23.9)$ \\
$50-200 \mathrm{~m}$ & $7.4(-0.3)$ & $6.2(0.5)$ & $7.7(3.9)$ & $4.8(7.5)$ & $4.9(4.9)$ & $3.6(1.4)$ & $5.4(-0.9)$ & $7.3(-1.2)$ & $10(26.4)$ \\
$200-500 \mathrm{~m}$ & $6.1(-1.8)$ & $4.2(0.9)$ & $5.9(1.9)$ & $3.1(6.2)$ & $3.2(5)$ & $2.6(1.2)$ & $6(-1.1)$ & $3.9(-1)$ & $19.2(28.8)$ \\
$>500 \mathrm{~m}$ & $6.4(-2.7)$ & $3.8(-1.6)$ & $6.6(-0.6)$ & $3.4(3.3)$ & $3.5(5.5)$ & $2.1(1.7)$ & $4.1(-0.4)$ & $3.1(1.9)$ & $-*$ \\
\hline
\end{tabular}

Table S2. Comparison between the $\mathrm{TCO}_{2}$ climatology of Lauvset et al. (2016) and the one of the present study at different depth levels.

\begin{tabular}{lccc}
\hline Depth layer & RMSE $\left(\mu \mathrm{mol} \mathrm{kg}{ }^{-1}\right)$ & Bias $\left(\mu \mathrm{mol} \mathrm{kg}^{-1}\right)$ & $\mathrm{r}^{2}$ \\
\hline 0 & 31.5 & -8.3 & 0.85 \\
100 & 15.9 & 0.9 & 0.95 \\
250 & 10.5 & 1.3 & 0.97 \\
500 & 7.6 & 1.0 & 0.99 \\
1000 & 6.8 & 0.4 & 0.99 \\
2000 & 4.8 & -0.4 & 0.995 \\
3000 & 5.3 & -1.4 & 0.993 \\
4000 & 5.4 & -1.2 & 0.99 \\
\hline
\end{tabular}


(a)

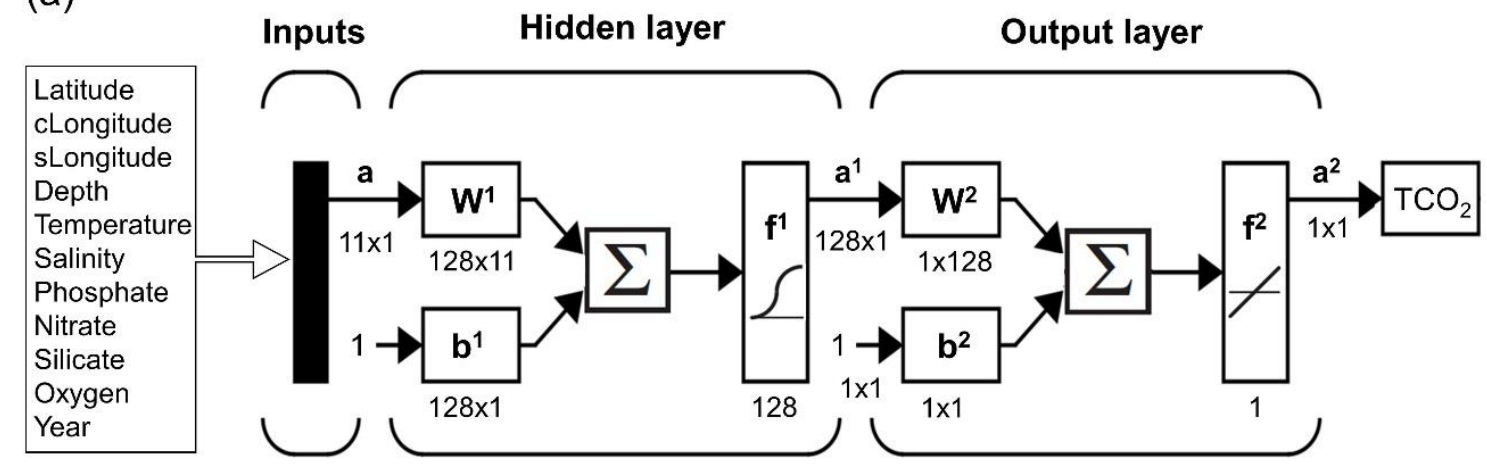

(b)

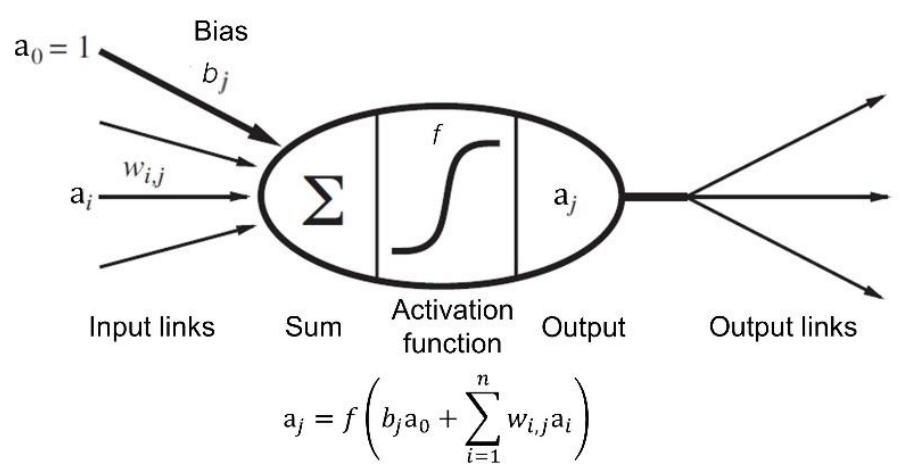

Figure S1. (a) Neural network configuration. The notation is in agreement with Hagan et al. (2014). a: input vectors; W: weight matrix; b: bias matrix; $\sum$ : sum; f: transfer function; $\mathbf{a}^{\mathbf{x}}$ : output matrix. The superscripts indicate the number of the layer. cLongitude $=\cos \left(\frac{\pi}{180^{\circ}}\right.$ longitude $) ;$ sLongitude $=\sin \left(\frac{\pi}{180^{\circ}}\right.$ longitude $)$. The dimensions of the matrices are for an individual sample. Modified from Hagan et al. (2014). (b) Neuron. ai: inputs to each neuron; $w_{i, j}$ : weights of each input to each neuron. Modified from Russell and Norvig et al. (2010). 


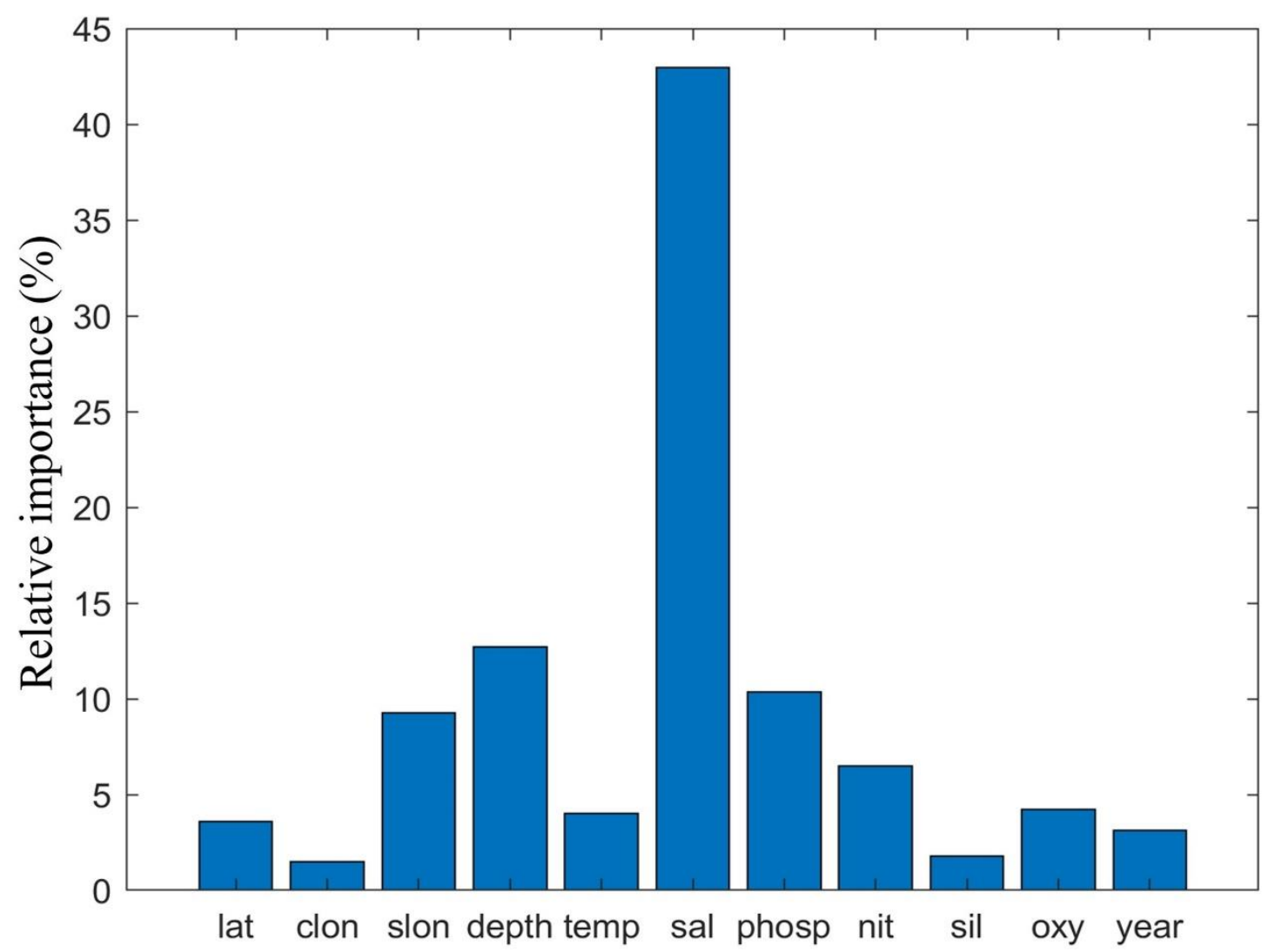

Figure S2. The relative importance of the input variables for NNGv2LDEO obtained with Eq. (1). lat: latitude; clon: clongitude; slon: slongitude; temp: temperature; sal: salinity; phosp: phosphate; nit: nitrate; sil: silicate; oxy: oxygen. 


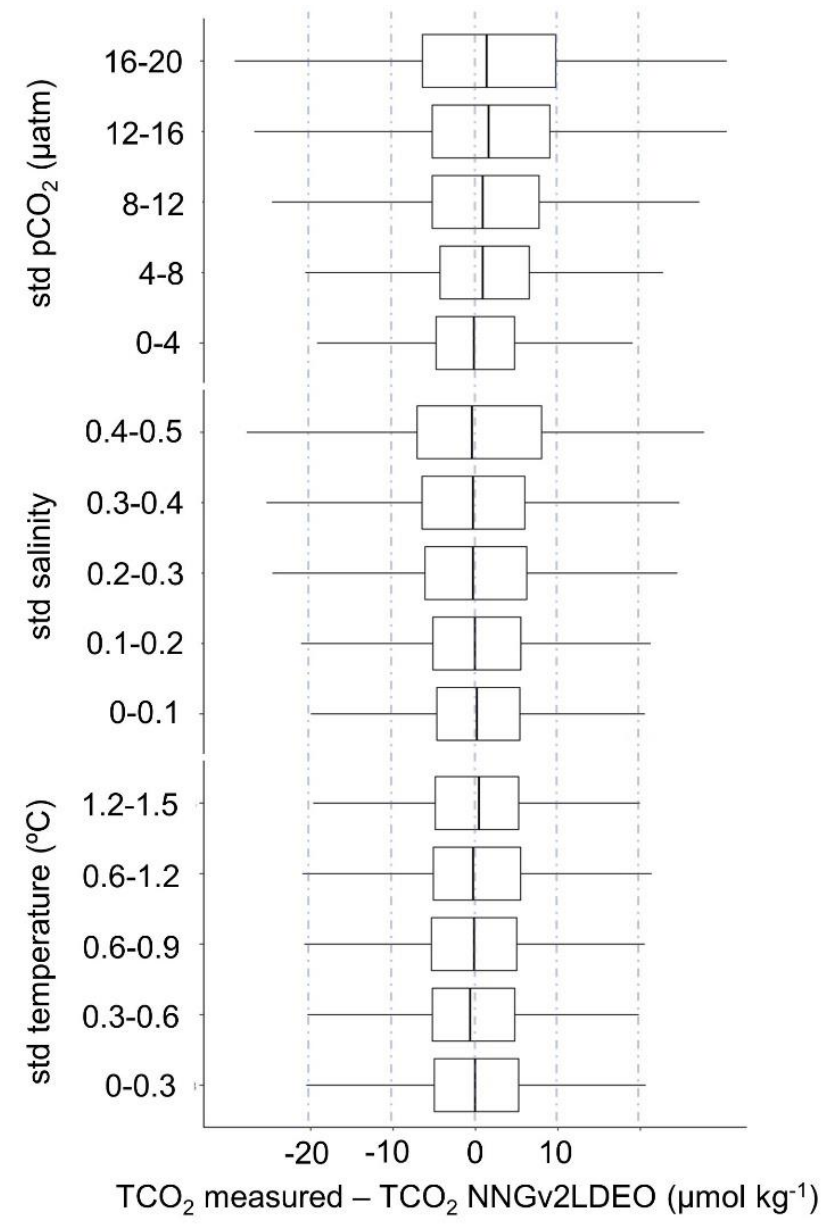

Figure S3. Box plots of differences between measured and computed $\mathrm{TCO}_{2}$ in $\mathrm{LDEO}$ by standard deviation (SD) ranges obtained from the monthly average of the LDEO data.

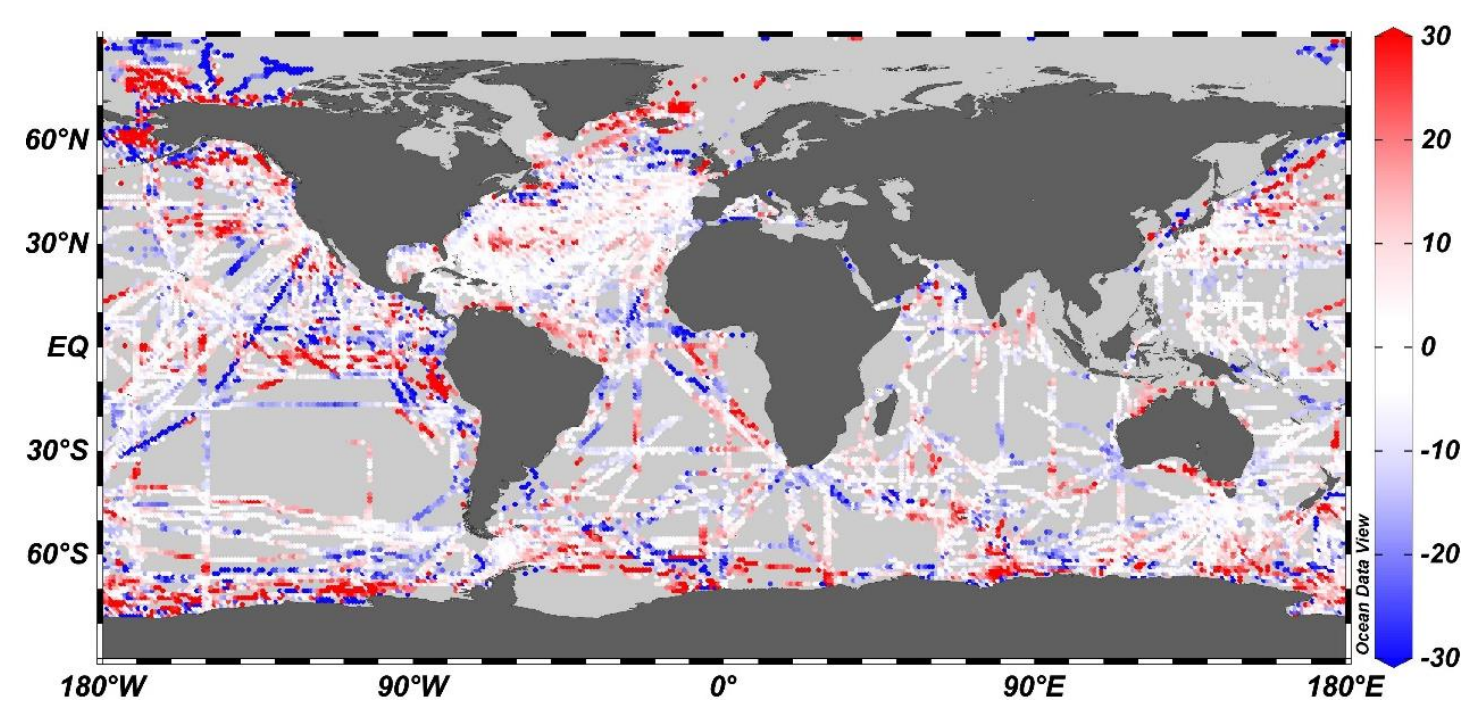

Figure S4. Differences between measured and computed $\mathrm{pCO}_{2}$ with $\mathrm{A}$ f from NNGv2 (Broullón et al., 2019) and $\mathrm{TCO}_{2}$ from NNGv2LDEO in LDEO. Units are microatmospheres $(\mu \mathrm{atm})$. This figure was made with Ocean Data View (Schlitzer, 2016). 


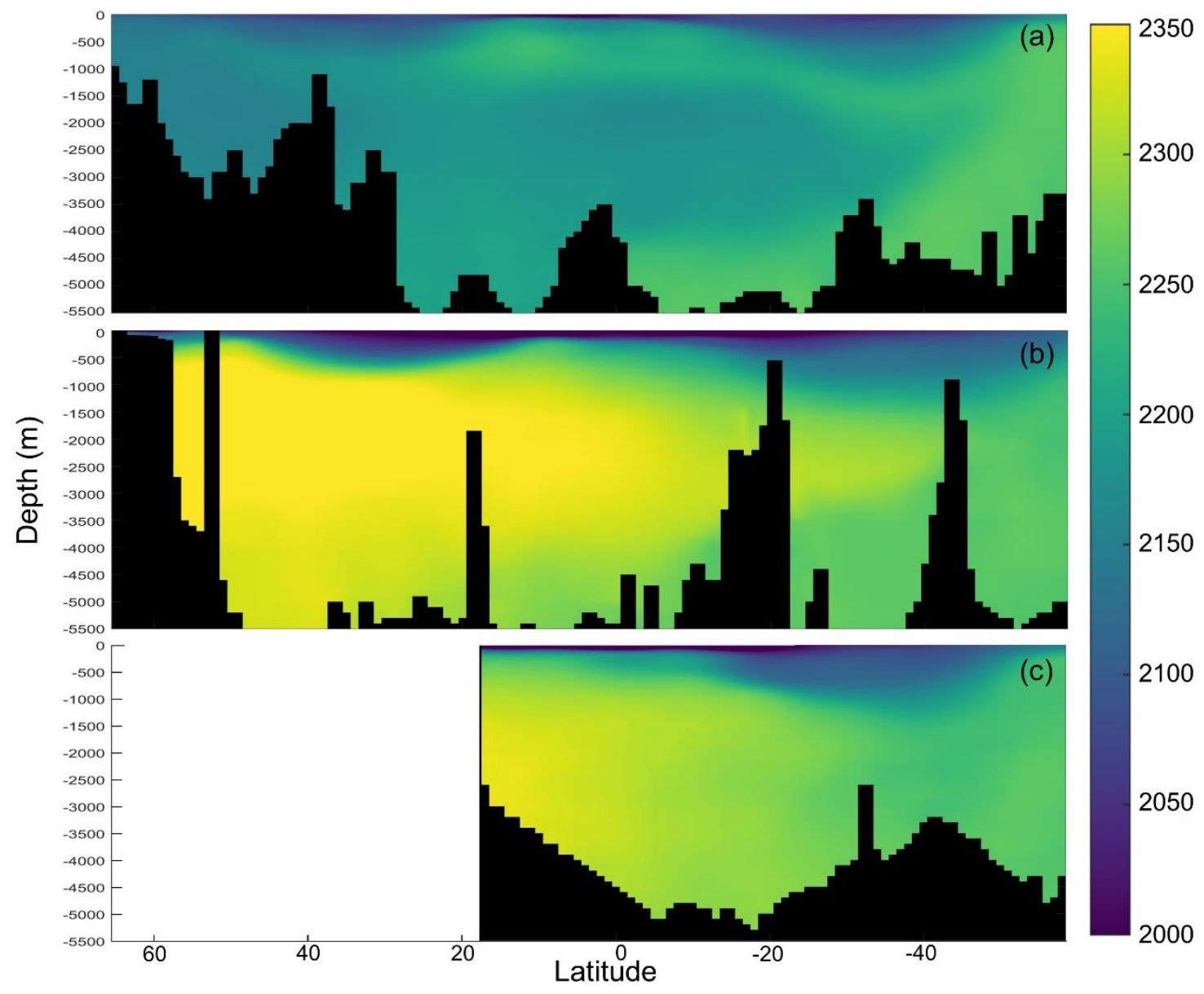

Figure S5. Sections of annual mean $\mathrm{TCO}_{2}$ from the neural network climatology in (a) Atlantic (longitude: $28.5^{\circ} \mathrm{W}$ ), (b) Pacific (longitude: $174.5^{\circ} \mathrm{W}$ ) and (c) Indian (longitude: $84.5^{\circ} \mathrm{E}$ ) oceans. Units are micromole per kilogram $(\mu \mathrm{mol}$ $\mathrm{kg}^{-1}$ ). 


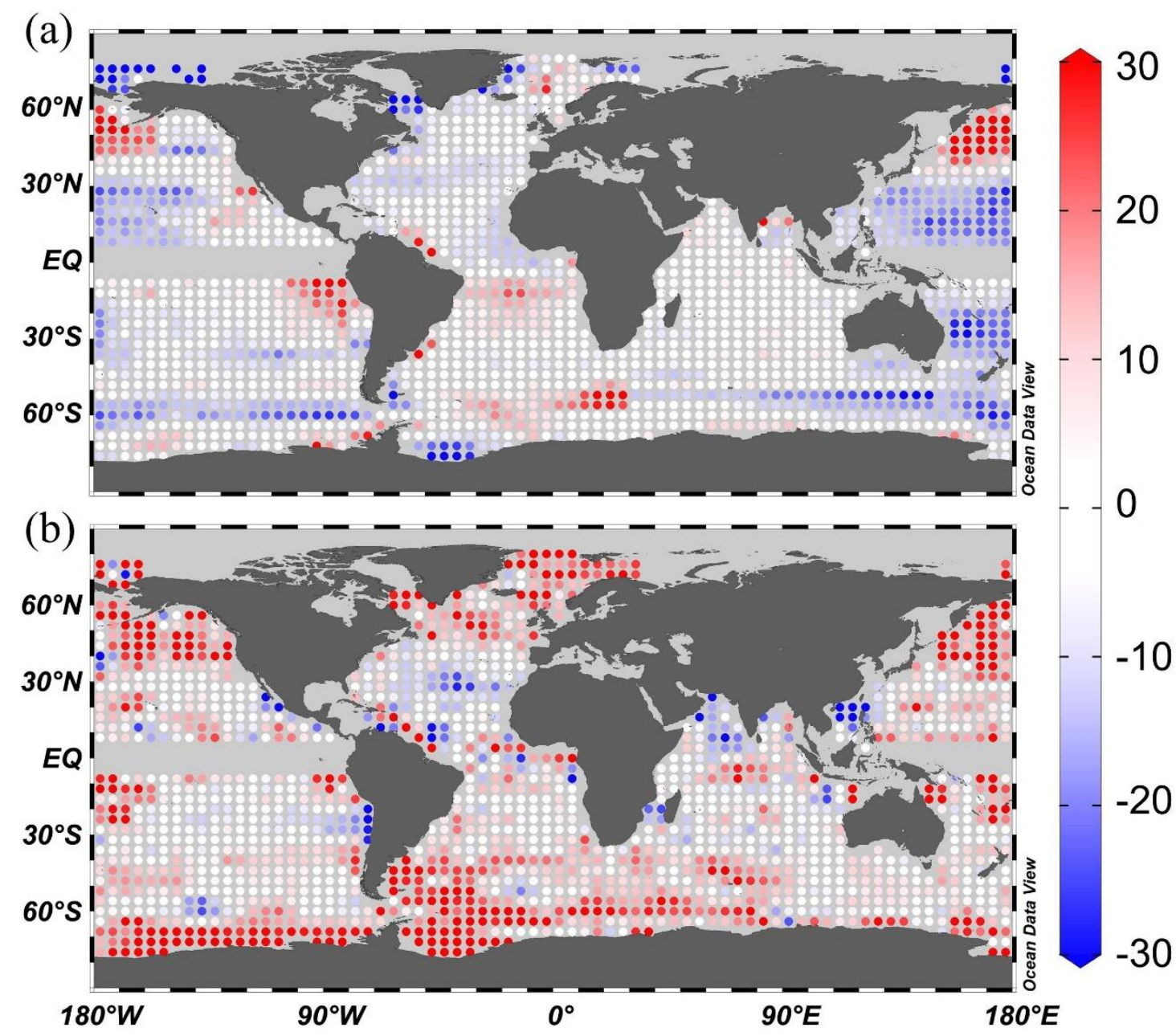

Figure S6. Differences between the annual mean of surface $\mathrm{TCO}_{2}$ neural network climatology and (a) Takahashi et al. (2014) and (b) Lauvset et al. (2016) surface annual mean climatology. Units are micromole per kilogram $\left(\mu \mathrm{mol} \mathrm{kg}{ }^{-1}\right)$. The color bar was developed in order to show the highest differences beyond the errors of each method. This figure was made with Ocean Data View (Schlitzer, 2016). 


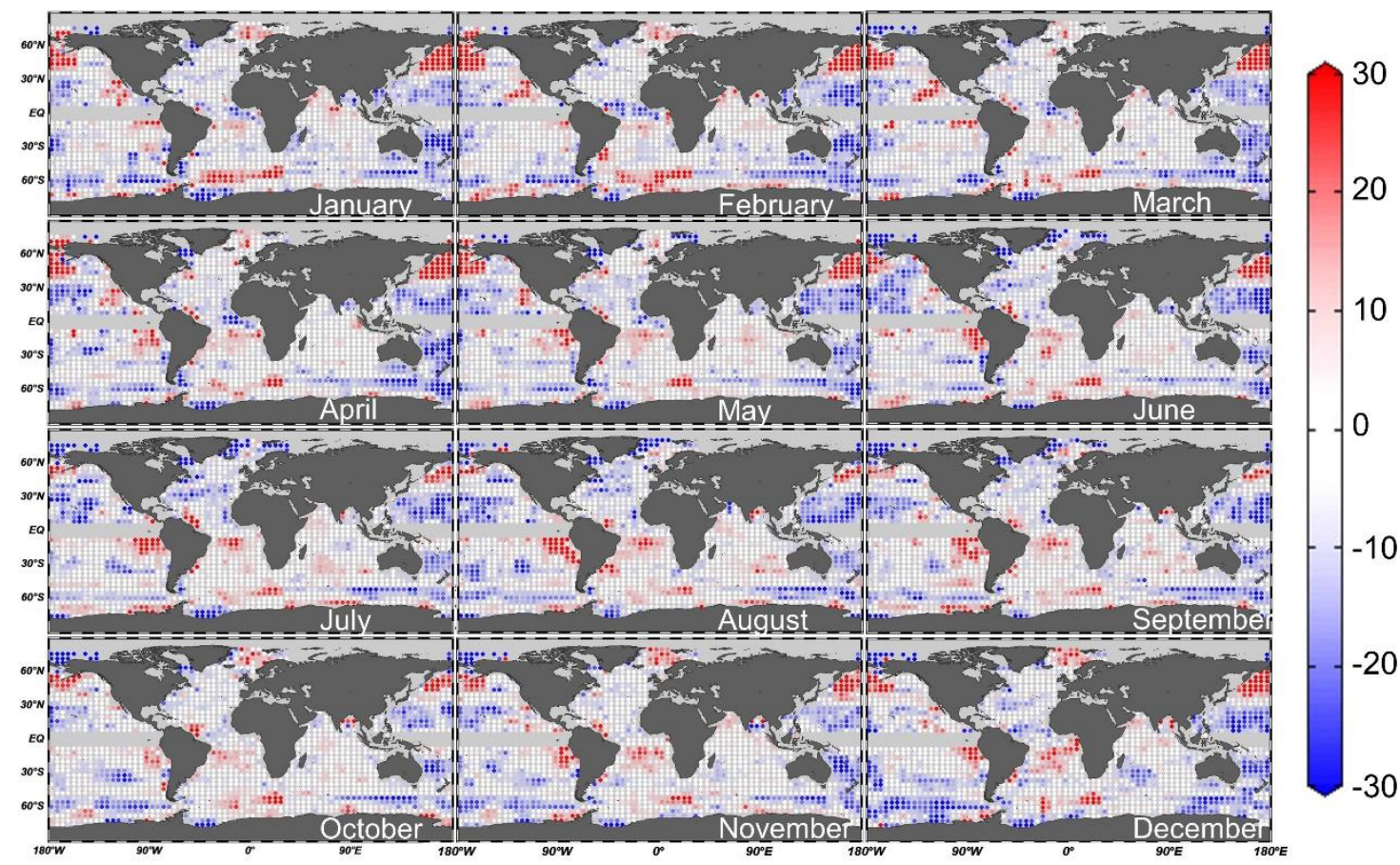

Figure S7. Differences between the monthly climatology of $\mathrm{TCO}_{2}$ of Takahashi et al. (2014) and the one of the present study. The color bar was developed in order to show the highest differences beyond the errors of each method. Units are micromole per kilogram $\left(\mu \mathrm{mol} \mathrm{kg}{ }^{-1}\right)$. This figure was made with Ocean Data View (Schlitzer, 2016).
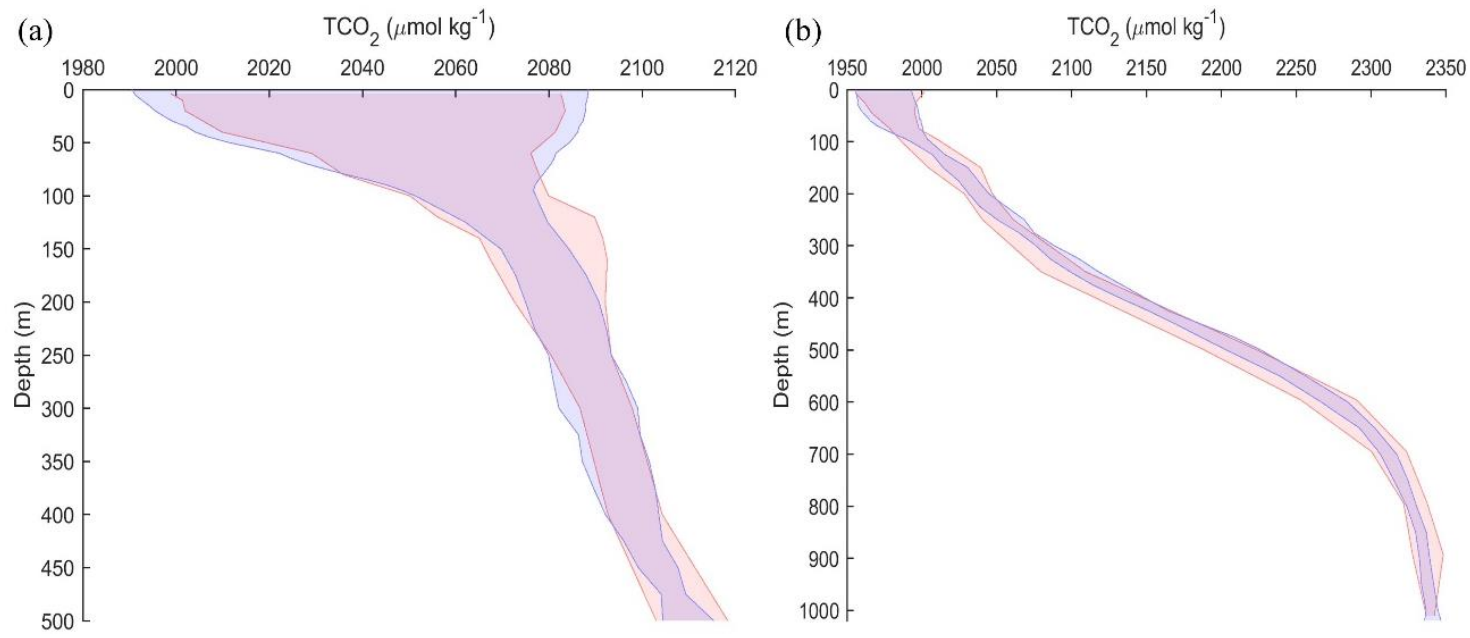

Figure S8. Profiles of the seasonal variability of the measured data (red lines and red shadow) and the $\mathrm{TCO}_{2}$ climatology (blue lines and blue shadow) at (a) BATS and (b) HOT ALOHA locations. The variability of the measured data was computed subtracting the maximum and the minimum $\mathrm{TCO}_{2}$ values of the measured climatological profiles depicted in Fig. 9. Note the different color of the overlapped area. 


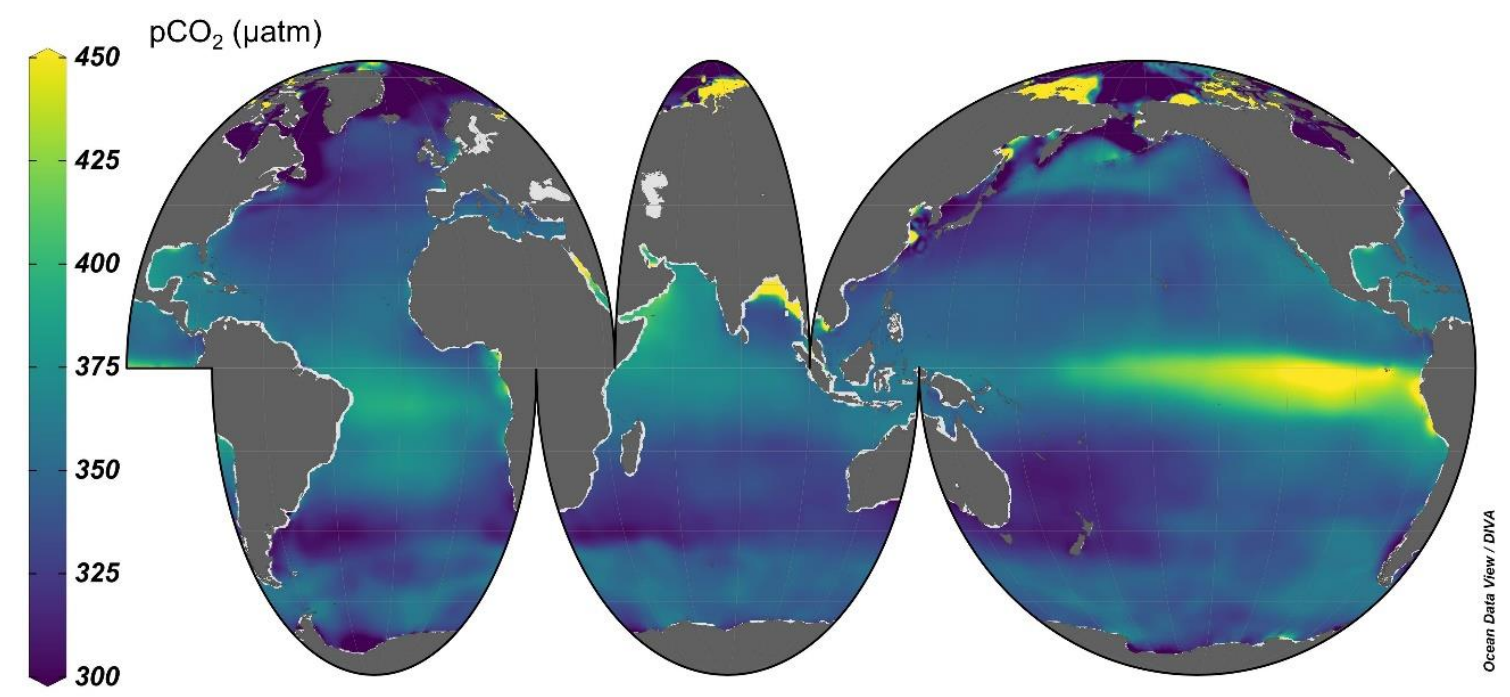

Figure S9. Annual mean $\mathrm{pCO}_{2}$ centered in 1995 computed from the annual mean $\mathrm{A}_{\mathrm{T}}$ (Broullón et al., 2019) and $\mathrm{TCO}_{2}$ (this study). It should be noted that the extremely high values in the coastal waters of the Arctic Ocean are derived from a $\mathrm{TCO}_{2} / \mathrm{A}_{\mathrm{T}}$ ratio higher than 1 . This fact is determined by the difficulty of neural networks to model both variables under the influence of river discharges with high concentrations of $\mathrm{A}_{\mathrm{T}}$ and $\mathrm{TCO}_{2}$, but $\mathrm{TCO}_{2} / \mathrm{A}_{\mathrm{T}}$ ratios higher than 1 are also found in the Arctic Ocean for the measured data in GLODAPv2.2019 (Olsen et al., 2019). This figure was made with Ocean Data View (Schlitzer, 2016).

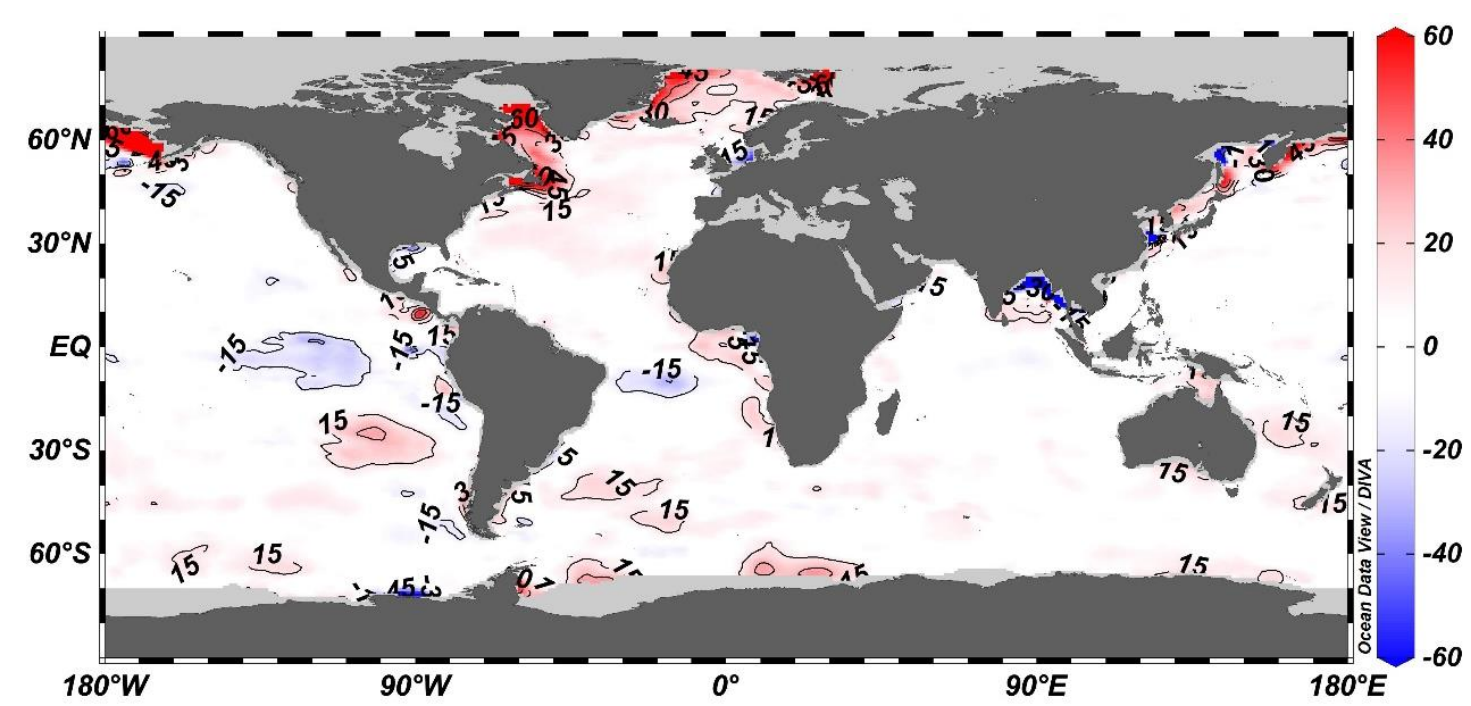

Figure S10. Differences between the annual mean climatology of $\mathrm{pCO}_{2}$ from Landschützer et al. (2017) centered in 1995 and the one computed in the present study. Units are microatmospheres ( $\mu \mathrm{atm}$ ). The contour lines of 15, 30, 45 and $60 \mu \mathrm{atm}$ are shown. This figure was made with Ocean Data View (Schlitzer, 2016). 


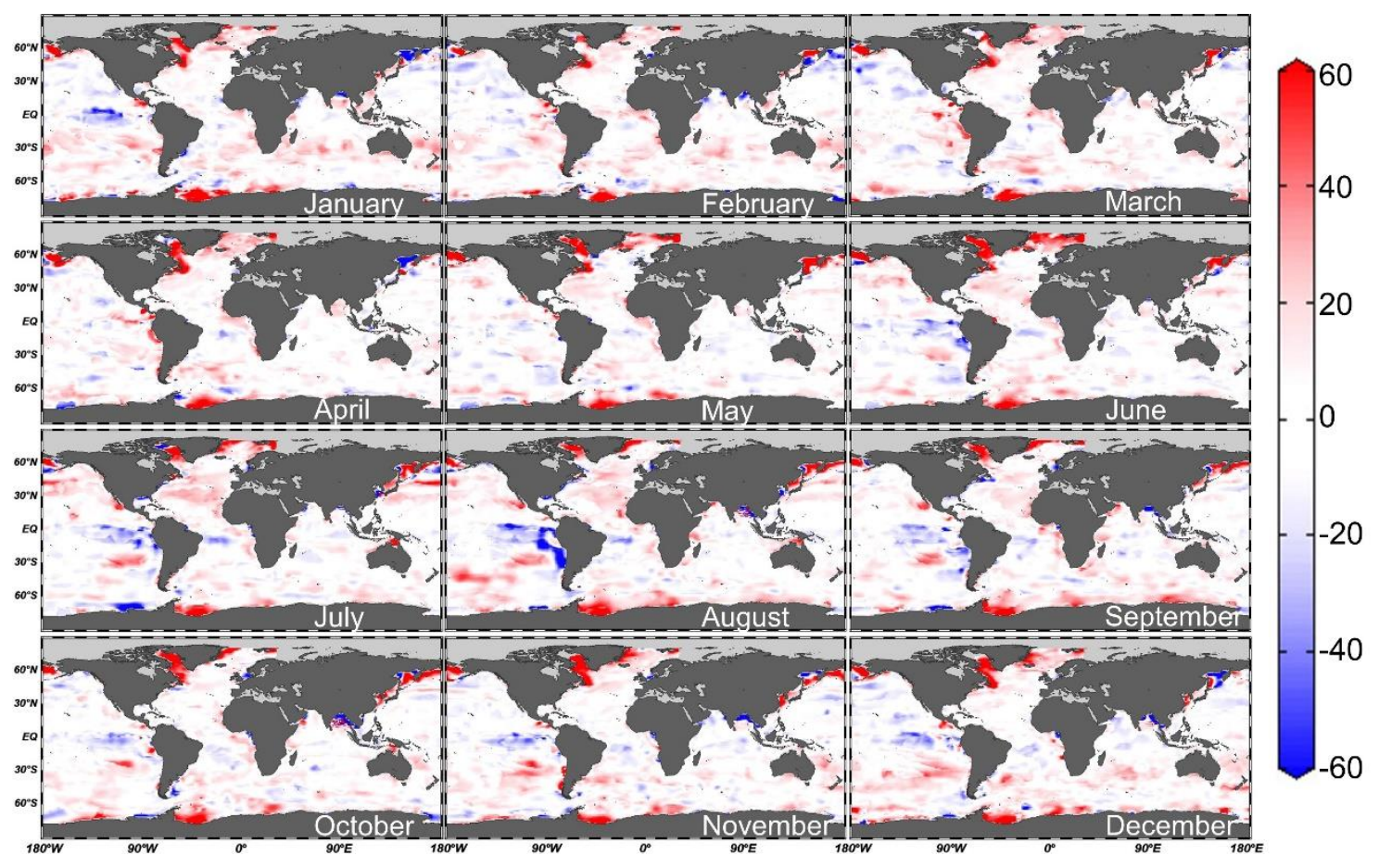

Figure S11. Differences between the monthly climatology of $\mathrm{pCO}_{2}$ from Landschützer et al. (2017) centered in 1995 and the one computed in the present study. Units are microatmospheres ( $\mu \mathrm{atm})$. The contour lines of 15, 30, 45 and 60 $\mu \mathrm{atm}$ are shown. This figure was made with Ocean Data View (Schlitzer, 2016).

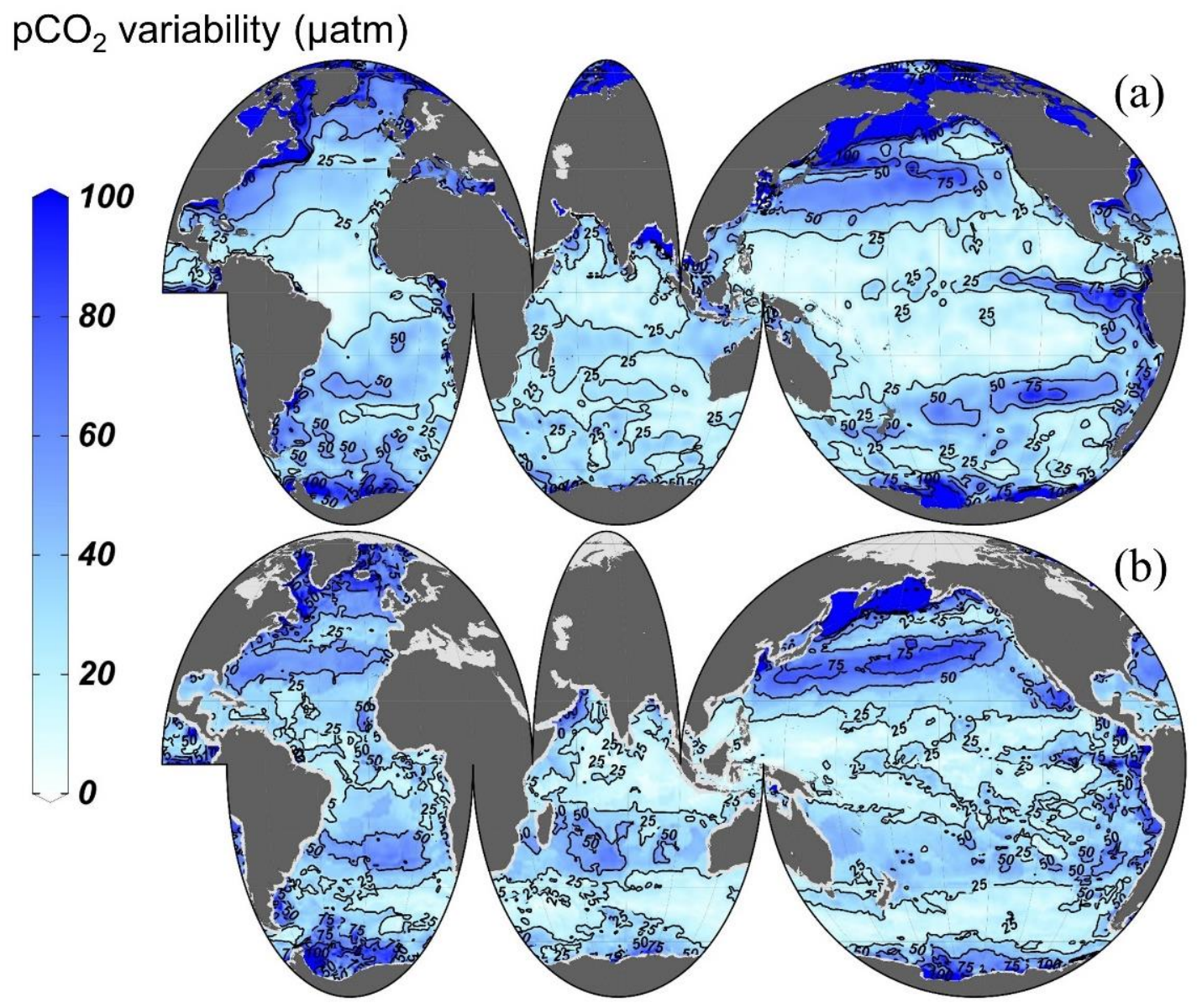

Figure S12. Seasonal amplitude of surface $\mathrm{pCO}_{2}$ of (a) this study and (b) Landschützer et al. (2017) centered in the year 1995. The contour lines of 25, 50, 75 and $100 \mu$ atm are shown. This figure was made with Ocean Data View (Schlitzer, 2016). 


\section{References}

Broullón, D., Pérez, F. F., Velo, A., Hoppema, M., Olsen, A., Takahashi, T., Key, R. M., Tanhua, T., González-Dávila, M., Jeansson, E., Kozyr, A. and van Heuven, S. M. A. C.: A global monthly climatology of total alkalinity: a neural network approach, Earth Syst. Sci. Data, 11(3), 1109-1127, doi:10.5194/essd11-1109-2019, 2019.

Hagan, M. T., Demuth, H. B., Beale, M. H., and De Jesus, O.: Neural network design, ISBN 9780971732117, available at: http://hagan.okstate.edu/nnd.html (last access: 26 July 2018), 2014.

Landschützer, P., Gruber, N. and Bakker, D.C.E.: An updated observation-based global monthly gridded sea surface $\mathrm{pCO}_{2}$ and air-sea $\mathrm{CO}_{2}$ flux product from 1982 through 2015 and its monthly climatology (NCEI Accession 0160558). Version 2.2. NOAA National Centers for Environmental Information. Dataset. [201707-11], (last access: 15 July 2019), 2017

Lauvset, S. K., Key, R. M., Olsen, A., Van Heuven, S., Velo, A., Lin, X., Schirnick, C., Kozyr, A., Tanhua, T., Hoppema, M., Jutterström, S., Steinfeldt, R., Jeansson, E., Ishii, M., Perez, F. F., Suzuki, T. and Watelet, S.: A new global interior ocean mapped climatology: The $1^{\circ} \times 1^{\circ}$ GLODAP version 2, Earth Syst. Sci. Data, 8(2), 325-340, doi:10.5194/essd-8-325-2016, 2016.

Russell, S. J. and Norvig, P.: Artificial intelligence: a modern approach, Prentice Hall, 2010.

Schlitzer, R., Ocean Data View, available at: http://odv.awi.de (last access: 21 May 2018), 2016. 